Journal of Engineering and Applied Sciences 15 (2): 365-368, 2020

ISSN: 1816-949X

(C) Medwell Journals, 2020

\title{
Empirical Models Share of Knowledge at Private University Lecturers in Maluku
}

\author{
${ }^{1}$ Conchita Valentina Latupapua, ${ }^{2}$ Armanu Thoyib, ${ }^{2}$ Djumilah Hadiwidjojo and ${ }^{3}$ Ir. Solimun \\ ${ }^{1}$ Faculty of Economics and Business, Pattimura University, Ambon, Indonesia \\ ${ }^{2}$ Faculty of Economics and Business, \\ ${ }^{3}$ Faculty of Mathematics, Brawijaya University, Malang, Indonesia
}

\begin{abstract}
The development of technology and information gives a special impact for organizational governance. Organization is seen as a body of knowledge that is composed of the knowledge of individuals residing within the organization. Knowledge-based activities of knowledge include creating and integrating knowledge, accumulation and use of knowledge and learning and sharing of knowledge known as knowledge management. Knowledge sharing can be defined as a process of sharing experiences and individual information undertaken within an organization. This study is conducted to find out the relationship between organizational trust with knowledge sharing behavior directly or mediated by organizational citizenship behavior and organizational commitment. The research was conducted on private university lecturers in Maluku. The number of lecturers involved as respondents is as many as 90 people.
\end{abstract}

Key words: Empirical model, knowledge sharing at university lecturer, Knowledge-based activities, citizenship, accumulation, commitment

\section{INTRODUCTION}

In the era of technology and information, knowledge is a very valuable resource. Knowledge is perceived as an important asset in the face of various competitions. Organizations are increasingly recognizing that knowledge is an important resource for organizational progress and sustainability. Organization is seen as a body of knowledge that is composed of the knowledge of individuals residing within the organization. Knowledge plays an important role in the decision-making process, the formulation of direction and strategy as well as creating innovations for organizational development (Razak et al., 2016). Therefore, organizations should be able to implement and enhance knowledge-based activities.

Knowledge-based activities of knowledge include creating and integrating knowledge, accumulation and use of knowledge and learning and sharing of knowledge known as knowledge management. Various literatures mention it sharing knowledge is a humanistic process influenced by factors such as strategy, structure and role, process, organizational culture, physical environment, structure and script, motivation and reward. This phenomenon can also be found in educational institutions such as universities.

Individual factors refer to a lack of communication skills, social networks, cultural differences, social status as well as lack of time and trust. At the organizational level, influencing factors are infrastructure and resources.
At technological level, the staff's is desire to use technology (Riege, 2005). Hsu et al. (2007) also explains that there are shared factors that influence the desire to share knowledge but in general are divided into two parts: factors that come from within a person and environmental factors. It is identifies several factors that affect knowledge sharing at university level.

\section{MATERIALS AND METHODS}

This study includes explanatory research with quantitative approach to analyze causality relationship between research variables: organizational belief, organizational civic behavior, organizational commitment and knowledge sharing behavior. The approach used in this research is a positivist approach with the characteristics of priority theory and previous research to build the concept and hypothesis framework; using quantitative analysis tools and concerned with the generalization of research results.

The research was conducted at Private Higher Education (PTS) in Maluku that exist in work area Kopertis XII Maluku and North Maluku. The selection of location in private universities in Maluku was greater than the PTS in North Maluku, the percentage of study program at quality level of excellent with the a score is still very small but however, the number of lecturers with the status of civil servants (DPK) is higher than the PTS lecturer. 
J. Eng. Applied Sci., 15 (2): 365-368, 2020

Table 1: Estimation path coefficient result of inner model

\begin{tabular}{lcccc}
\hline Variable and relations & Path coefficient & SD & p-values & Description \\
\hline Org. trust-> Knowledge share behaviour & 0.14 & 0.088 & 0.08 & Not support \\
Org. trus ->Org. Com. & 0.68 & 0.094 & $<0.01$ & Support \\
Org. trust->OCB & 0.66 & 0.087 & $<0.01$ & Support \\
Org. com->Knowledge share behaviour & 0.41 & 0.087 & $<0.01$ & Support \\
OCB ->Knowledge share behaviour & 0.34 & 0.095 & $<0.01$ & Support \\
\hline
\end{tabular}

Table 2: Mediation variable classifications

\begin{tabular}{llr}
\hline No. & Statistical test & Type of meditations \\
\hline 1 & (c): Significant & Full mediation \\
& (d): Significant & \\
& (a): Not significant & \\
& (c): Significant & Partial mediation \\
3 & (d): Significant & No mediation \\
& (a): Significant $\mid$ (a) $<$ (b) & \\
& (c): Significant & (d): Significant \\
& (a): Not signifikan & (c)/(d): Not significant \\
& (a): Significant & No mediation \\
\hline
\end{tabular}

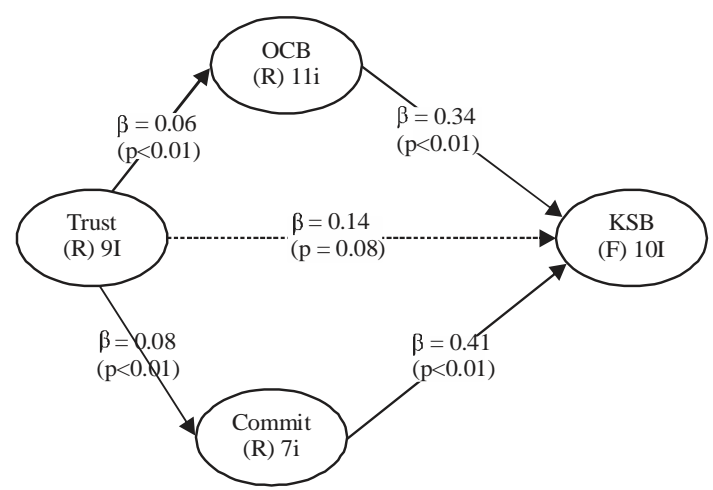

Fig. 1: Analysis result knowledge sharing model

\section{RESULTS AND DISCUSSION}

Structural model testing can be evaluated by looking at the coefficient value of the relationship path between latent variables. Structural model testing is done after the research model is built is in accordance with the observation data and suitability of the overall model or goodness-of-fit has been met well. The purpose of testing the relationship model existing in the structural model is to determine the relationship between latent variables that have been designed in this study. Structural model testing is based on Wrap PLS 5.0 output by looking at the estimated path coefficient and significant critical value at $\alpha=0.05$. Based on the conceptual framework of the research that has been built, the conceptual framework model testing in this research can be done with three stages: direct impact path coefficient test, testing of path coefficient of influence of mediation variable and testing of path coefficient.

Hypothesis testing is based on the result of SEM PLS model analysis which contains all supporting variables hypothesis test. The PLS model with the addition of organizational civic behavior variable and organizational commitment as the mediating variable explains that adding variables will contribute additional as an explanation of knowledge sharing behavior. In this mediation model there is some information obtained in the analysis.

Table 1 shows the path coefficient between the organizational trust variable and the knowledge-sharing behavior directly or with the variable between the organizational citizenship behavior as well as the organizational commitment variable and the relationship between the variables between the knowledge sharing behaviors. In addition, the analysis is also conducted to see the role of intermediate variables in mediating the relationship between organizational beliefs and knowledge-sharing behaviors. Theoretically, the classification of mediation variables is presented in Table 2.

Based on the results of the data analysis shown in Fig. 1 shows that the coefficient of the relationship path between the trust of the organization and the knowledge sharing behavior is 0.14 with the significance level (p-value) 0.08 which is greater than the value of $\alpha=0.05$. These results prove that there is no significant positive relationship between organizational trust and knowledge sharing behavior in private universities in Maluku. Thus, the research hypothesis of the direct relationship between organizational trust and knowledge sharing behavior is unacceptable. This study shows different results with some previous studies such as Holste and Fields (2010) and Khanmohammadi (2014). On the other hand, the results of this study reinforced the studies conducted by Chiang et al. (2011) who found that belief. 
J. Eng. Applied Sci., 15 (2): 365-368, 2020

Table 3: Meditation variable relation and detection

\begin{tabular}{|c|c|c|c|c|c|}
\hline \multirow{7}{*}{ Meditation path } & Pathr & Coefficient & $\mathrm{p}$-value & Description & Kesimpulan \\
\hline & (a) & 0.14 & 0.08 & Not support & Full meditation \\
\hline & (c) & 0.66 & $<0.01$ & Support & \\
\hline & (d) & 0.34 & $<0.01$ & Support & \\
\hline & (a) & 0.14 & 0.08 & Not support & Full meditation \\
\hline & (c) & 0.68 & $<0.01$ & Support & \\
\hline & (d) & 0.41 & 0.035 & Support & \\
\hline
\end{tabular}

Description: 1: Org. trust, 2: Knowledge sharing behavior, 3: OCB, 4: Org. commitment

There are 2 mediation tests in this stage, namely: organizational citizenship behavior as a mediation of relationships between organizational beliefs and behavioral sharing of knowledge of deviant behavior in the workplace and organizational commitment as mediating the relationship between organizational belief and knowledge-sharing behavior. After going through the analysis process known result of coefficient difference as described below.

Relationship between organizational trust and knowledge sharing behavior: Based on the results of the data analysis shown in Fig. 1 shows that the coefficient of the relationship path between the trust of the organization and the knowledge sharing behavior is 0.14 with the significance level (p-value) 0.08 which is greater than the value of $\alpha=0.05$. These results prove that there is no significant positive relationship between organizational trust and knowledge sharing behavior in private universities in Maluku. Thus, the research hypothesis of the direct relationship between organizational trust and knowledge sharing behavior is unacceptable. This study shows different results with some previous studies such as Holste and Fields (2010) and Khanmohammadi (2014). On the other hand, the results of this study reinforced the studies conducted by Chiang et al. (2011) who found that belief.

The influence of organizational beliefs on knowledge sharing behavior mediated by organizational citizenship behavior: Based on the results of mediation analysis presented in Table 3, it can be explained the relationship between organizational beliefs on knowledge-sharing behavior mediated by organizational citizenship behavior. The results of the analysis show that the relationship between organizational belief and knowledge-sharing behavior is insignificant while the relationship between organizational trust and organizational citizenship behavior is significant and the relationship between organizational civic behavior and knowledge sharing behavior is significant. On the basis of the results of the analysis can be concluded that the relationship is a perfect type of mediation. Thus, the hypothesis of the relationship between organizational belief and knowledge-sharing behavior mediated by organizational citizenship behavior is acceptable.

The influence of organizational beliefs on knowledge-sharing behavior is mediated by organizational commitment: The results of the mediation analysis presented in Table 3 can also be explained the relationship between organizational beliefs and knowledge-sharing behaviors mediated by organizational commitment. The results of the analysis suggest that the relationship between organizational belief and knowledge-sharing behavior is insignificant whereas the relationship between organizational trust and organizational commitment is significant and the relationship between organizational commitment and knowledge sharing behavior is also significant. On the basis of these results, it can be concluded that the type of mediation is perfect mediation. Thus, the hypothesis that the relationship between organizational beliefs is mediated by organizational commitment is acceptable. This result suggests that without organizational commitment the relationship between organizational beliefs is incapable of encouraging behavior.

\section{CONCLUSION}

Based on the results of data analysis and discussion that has been presented in the previous section it can be concluded that: there is no significant positive relationship between organizational trust with knowledge sharing behavior at private universities in Maluku, organizational citizenship behavior mediate the relationship between trust organizational and knowledge-sharing behaviors with the perfect type of mediation and organizational commitment mediates the relationship between organizational belief and knowledge-sharing behavior with the perfect type of mediation. 


\section{REFERENCES}

Chiang, H.H., T.S. Han and J.S. Chuang, 2011. The relationship between high-commitment HRM and knowledge-sharing behavior and its mediators. Int. J. Manpower, 32: 604-622.

Holste, J.S. and D. Fields, 2010. Trust and tacit knowledge sharing and use. J. Knowl. Manage., 14: $128-140$.

Hsu, M.H., T.L. Ju, C.H. Yen and C.M. Chang, 2007. Knowledge sharing behavior in virtual communities: The relationship between trust, self-efficacy and outcome expectations. Intl. J. Hum. Comput. Stud., 65: 153-169.
Khanmohammadi, M., 2014. Moderating role of the perceived justice in the relationship of trust, management support, individual attitude and reward system with universities lecturers knowledge sharing. Interdiscip. J. Contemp. Res. Bus., 7: 123-136.

Razak, A.A., M. Rowling, G. White and R. MasonJones, 2016. Public sector supply chain management: A triple helix approach to aligning innovative environmental initiatives. Foresight STI Guidance, 10: 43-52.

Riege, A., 2005. Three-dozen knowledge-sharing barriers managers must consider. J. Knowledge Manage., 9: 18-35. 